\title{
Los Morteros: exploraciones geoarqueológicas y paleoambiente de un montículo temprano, valle de Chao, costa norte del Perú
}

\section{Ana Cecilia Mauricio Llonto}

\section{(2) OpenEdition Journals}

Edición electrónica

URL: http://journals.openedition.org/bifea/4417

DOI: $10.4000 /$ bifea. 4417

ISSN: 2076-5827

Editor

Institut Français d'Études Andines

Edición impresa

Fecha de publicación: 1 mayo 2014

Paginación: 161-169

ISSN: 0303-7495

\section{Referencia electrónica}

Ana Cecilia Mauricio Llonto, «Los Morteros: exploraciones geoarqueológicas y paleoambiente de un montículo temprano, valle de Chao, costa norte del Perú », Bulletin de l'Institut français d'études andines [En línea], 43 (1) | 2014, Publicado el 08 mayo 2014, consultado el 06 noviembre 2020. URL : http:// journals.openedition.org/bifea/4417 ; DOI : https://doi.org/10.4000/bifea.4417

\section{(c)}

Les contenus du Bulletin de l'Institut français d'études andines sont mis à disposition selon les termes de la licence Creative Commons Attribution - Pas d'Utilisation Commerciale - Pas de Modification 4.0 International. 


\section{Avances de investigación}





\title{
Los Morteros: exploraciones geoarqueológicas y paleoambiente de un montículo temprano, valle de Chao, costa norte del Perú
}

\author{
Ana Cecilia Mauricio Llonto*
}

\section{INTRODUCCIÓN}

Los Morteros es un sitio arqueológico con forma de montículo de grandes dimensiones (200 m x $100 \mathrm{~m} \times 15 \mathrm{~m}$ ), que se encuentra situado en el valle bajo de Chao, costa norte del Perú (fig. 1). Específicamente, Los Morteros se ubica en la zona denominada Pampa de las Salinas, la cual es un área relativamente plana, caracterizada por la hiperaridez de sus tierras. Pampa de las Salinas está delimitada al sur y al este por estribaciones andinas; $8 \mathrm{~km}$ al norte se encuentra el río Chao y 4 km al oeste el Océano Pacícfico. Una particularidad de Pampa de las Salinas es la presencia de una línea de playa antigua en forma de herradura, la cual delinea una pequeña paleobahía, donde se encuentra una salina que fue explotada por el Estado peruano hasta principios de la década de 1970 (Cárdenas, 1999). Pampa de las Salinas es una zona arqueológica bastante interesante pues, a pesar de su actual aridez y aspecto desolado, concentra la mayor cantidad de sitios arqueológicos tempranos del valle de Chao, pues solo en esta área se han registrado más de 22 sitios arqueológicos, la mayoría de los cuales pertenecen al Periodo Precerámico Tardío (fig. 2).

Pampa de las Salinas fue explorada a fines de la década de 1970 por un equipo de arqueólogos liderado por Mercedes Cárdenas, dentro del marco del Proyecto «Obtención de una Cronología para el uso de los Recursos Marinos en el Antiguo Perú», el cual exploró diversos sitios de la costa peruana. En aquella oportunidad se

*University of Maine, 5773 South Stevens Hall, Orono, Maine 04469. E-mail: Ana_Mauricio@umit. maine.edu 


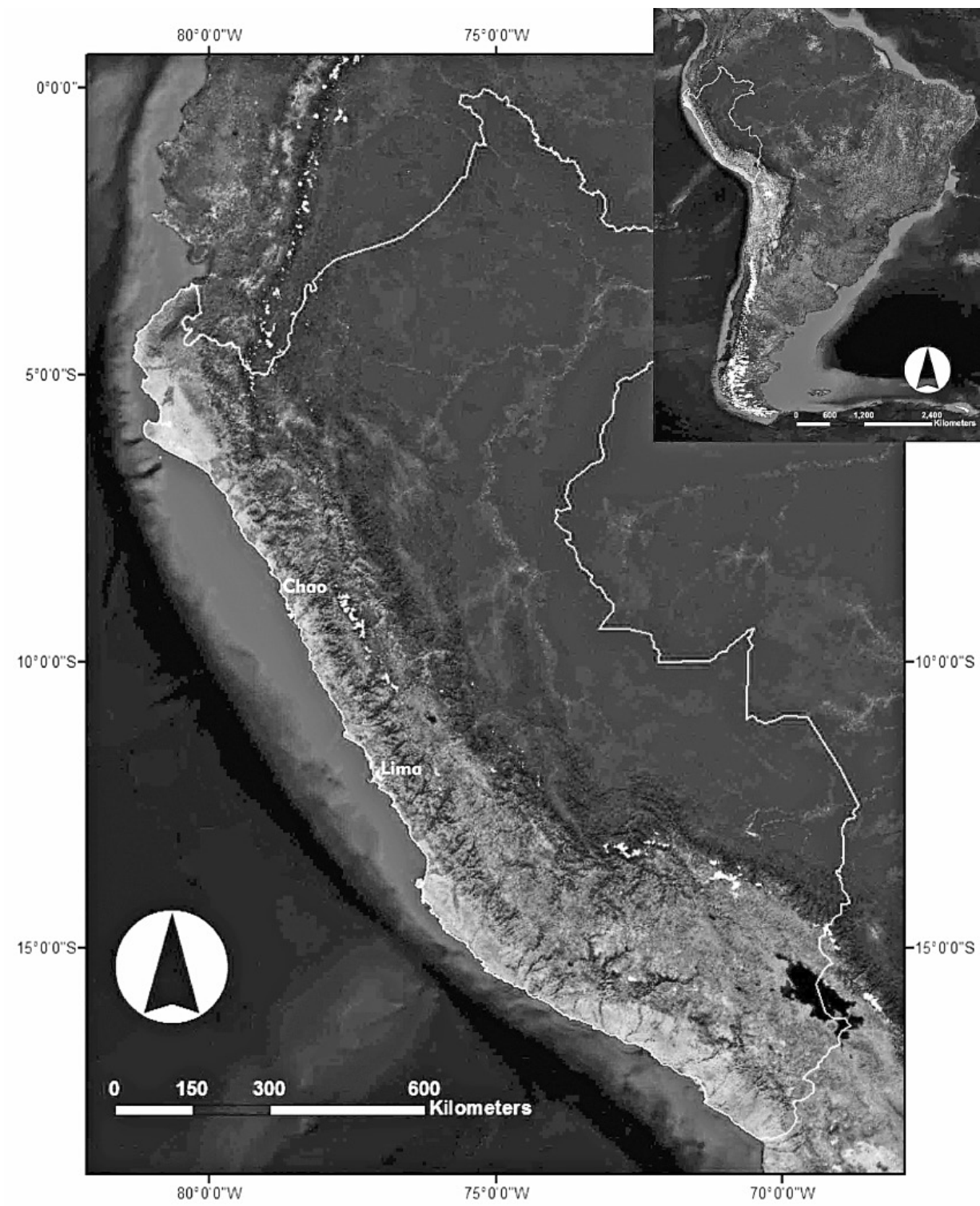

Figura 1 - Localización del sitio arqueológico Los Morteros en el territorio peruano

excavaron 12 pequeños cateos en la cima del montículo de Los Morteros y en varios otros sitios aledaños, realizando exploraciones intensivas solo en el sitio Salinas de Chao (Cárdenas, 1999; Alva, 1986). Las excavaciones en Los Morteros dieron como resultado el hallazgo de 7 entierros humanos precerámicos, y restos de ocupaciones domésticas asociados a actividades pesqueras. Dos fechados obtenidos en aquel 

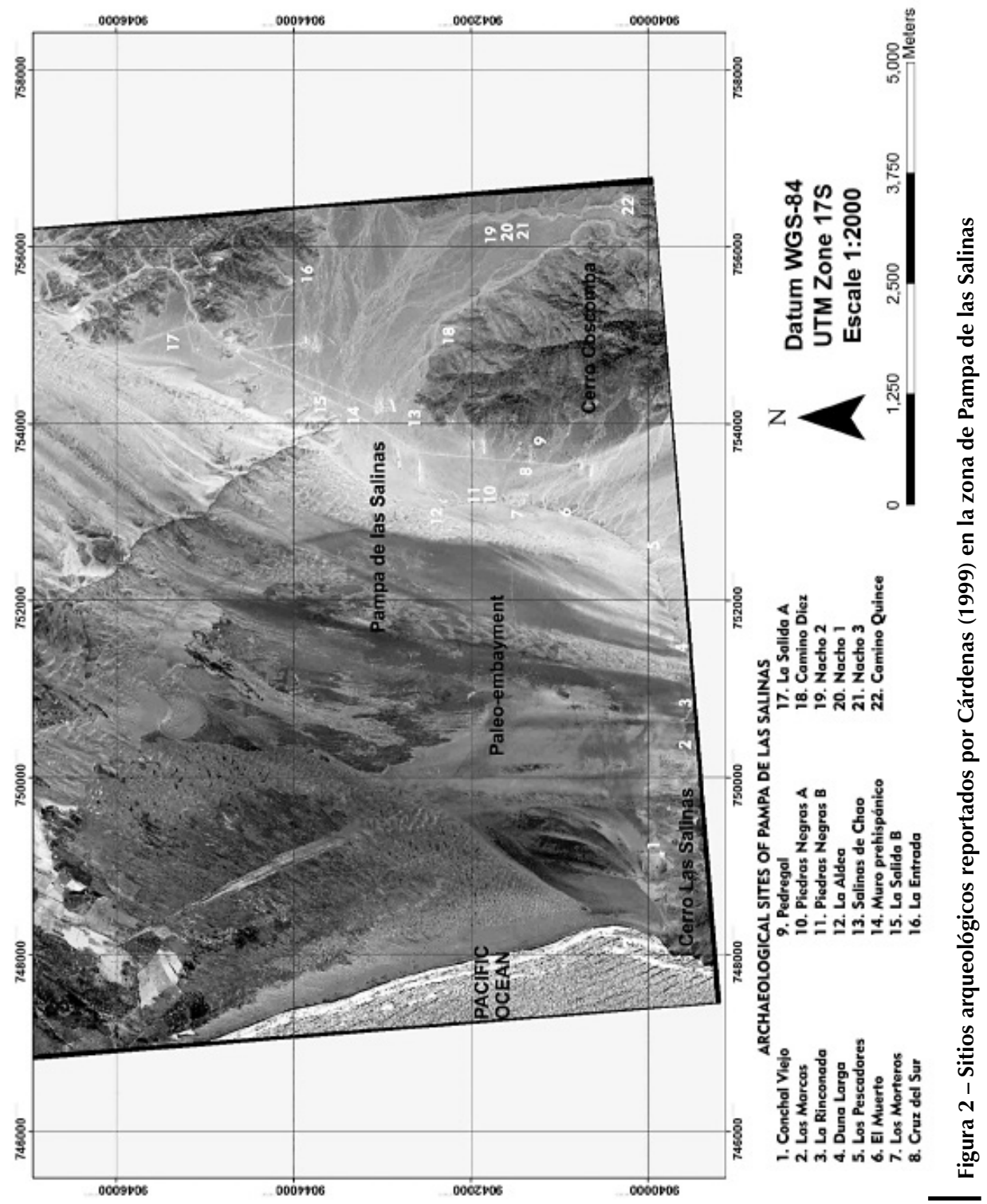
entonces en base a carbón vegetal, fecharon este sitio en ca. 5000 AP (2 sigma). En base a esos hallazgos, Cárdenas y su equipo clasificaron a Los Morteros como una duna estabilizada cuya cima había sido usada como cementerio por poblaciones de pescadores del Precerámico Tardío (Cárdenas, 1999).

Posteriormente, en los años 2006 y 2010, un equipo de la Universidad de Maine (EE.UU.) realizó exploraciones con georadares sobre el sitio Los Morteros, hallando evidencia de arquitectura subyacente a gruesas capas de arena eólica (Sandweiss et al., 2010). En 2012, el «Proyecto Arqueológico Los Morteros-Pampa de las Salinas», inició trabajos de campo en la zona de Pampa de las Salinas, centrándose en el sitio Los Morteros. Dichos trabajos se llevaron a cabo como parte de la investigación doctoral de la autora, la cual se encuentra aún en curso.

\section{TRABAJO DE CAMPO Y RESULTADOS PRELIMINARES}

En setiembre de 2012 se iniciaron las investigaciones de campo del Proyecto Arqueológico Los Morteros-Pampa de las Salinas, las cuales se prolongaron por un lapso de 5 meses hasta fines de enero de 2013. Los objetivos centrales de esta investigación son: 1) descubrir la arquitectura detectada a través de georadares; 2) hacer una primera aproximación de la secuencia de formación y transformación de Los Morteros; 3) estudiar la base económica de Los Morteros a través del tiempo; 4) hacer una primera aproximación de la secuencia de ocupación prehistórica de Pampa de las Salinas, con énfasis en aquellos sitios que puedan ser contemporáneos a Los Morteros, de modo que pueda estudiarse a este sitio en relación con su entorno cultural; 5) hacer una primera aproximación de la reconstrucción del tipo de medio ambiente que alojó el desarrollo temprano de sitios como Los Morteros.

Con estos objetivos se plantearon 3 componentes de investigación: 1) excavaciones arqueológicas intensivas en Los Morteros y pozos de cateo en cinco sitios aledaños (posiblemente contemporáneos); 2) exploraciones geoarqueológicas de la paleobahía y 3) exploraciones geoarqueológicas de las zonas cercanas a Pampa de las Salinas.

Las excavaciones en Los Morteros han descubierto una compleja historia de ocupación del sitio, la cual incluye arquitectura con características monumentales. Estas excavaciones indican que la ocupación humana de Los Morteros habría empezado como un pequeño montículo doméstico donde sus pobladores vivían explotando los recursos marinos de la antigua bahía, cuando el mar estuvo más cerca del sitio. La evidencia de este periodo consiste en una serie de fogones encontrados en los depósitos más profundos del montículo, hasta la fecha excavados; estos depósitos se hallaron en el sector más bajo del montículo, el sector central. Posteriormente, los habitantes de Los Morteros construyeron ambientes cuidadosamente hechos con adobes, con paredes enlucidas y gruesos pisos de arcilla, los cuales fueron usados para fines no domésticos, aparentemente ceremoniales (fig. 3); estos hallazgos se realizaron en las excavaciones del sector noroeste del montículo. La última fase de uso de este sitio consiste en arquitectura 

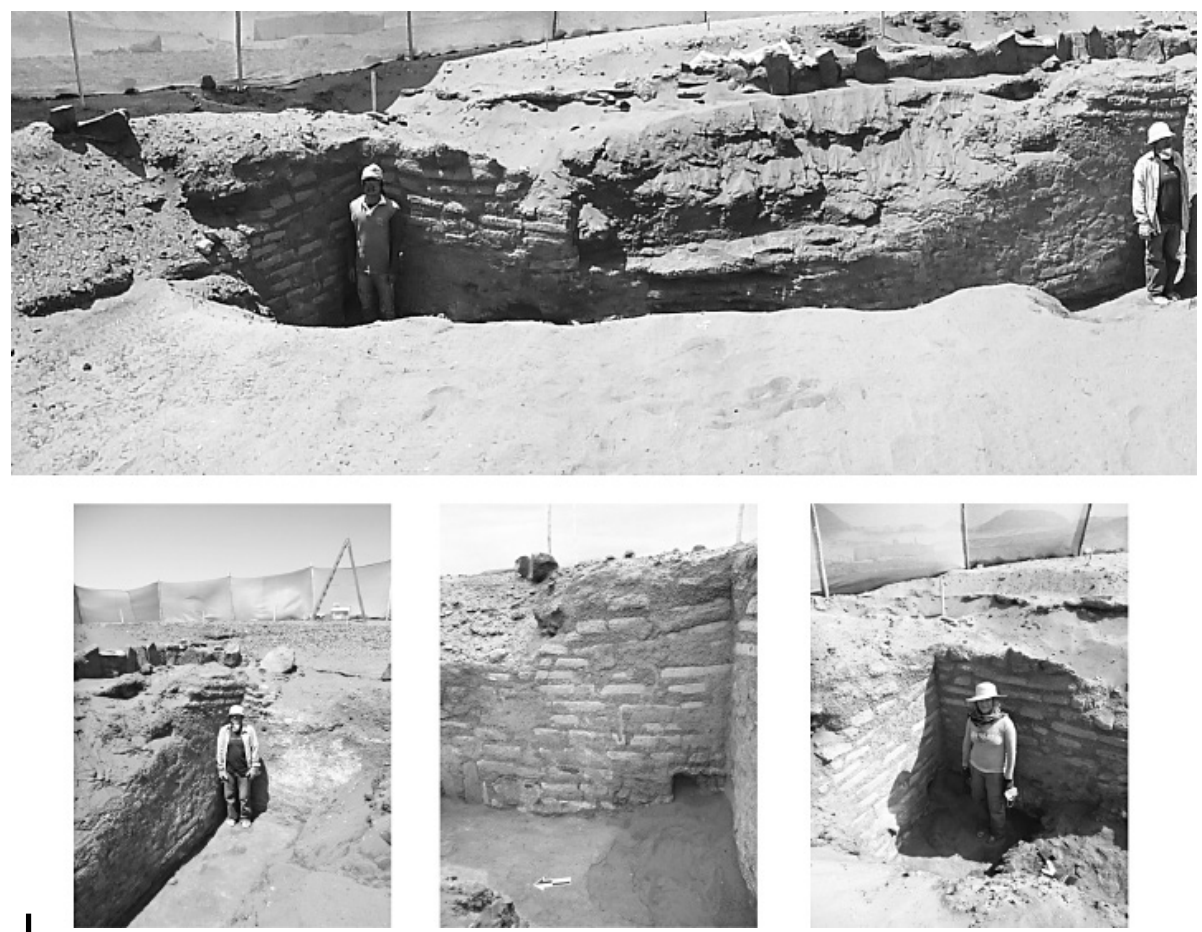

Figura 3 - Detalles de la arquitectura de adobe, arcilla y piedra hallada en el sitio Los Morteros

superficial, hecha con piedra y arcilla que parece relacionarse con algunos de los entierros excavados en los años 1970, y con los morteros de piedra que se pueden observar en la superficie de muchos sectores del montículo (fig. 4). Esta ocupación se registró en la cima del montículo, aunque hay restos del mismo tipo de arquitectura en la superficie de los sectores noreste y noroeste - en este último sector la arquitectura tardía de piedra se superpone a la arquitectura de adobe- (fig. 5).

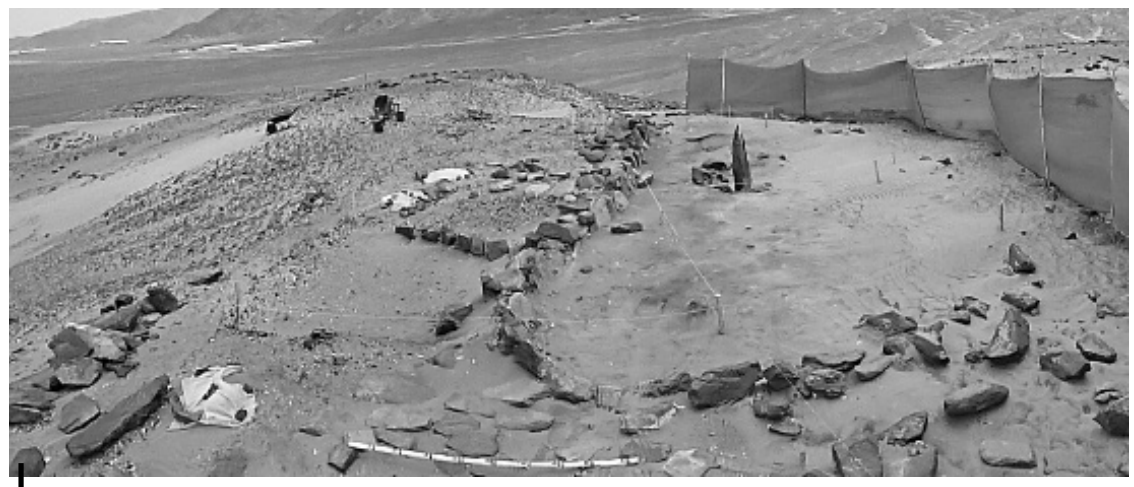

Figura 4 - Arquitectura tardía de piedra localizada en la cima del montículo Los Morteros, se trataría de una de las últimas ocupaciones del sitio 


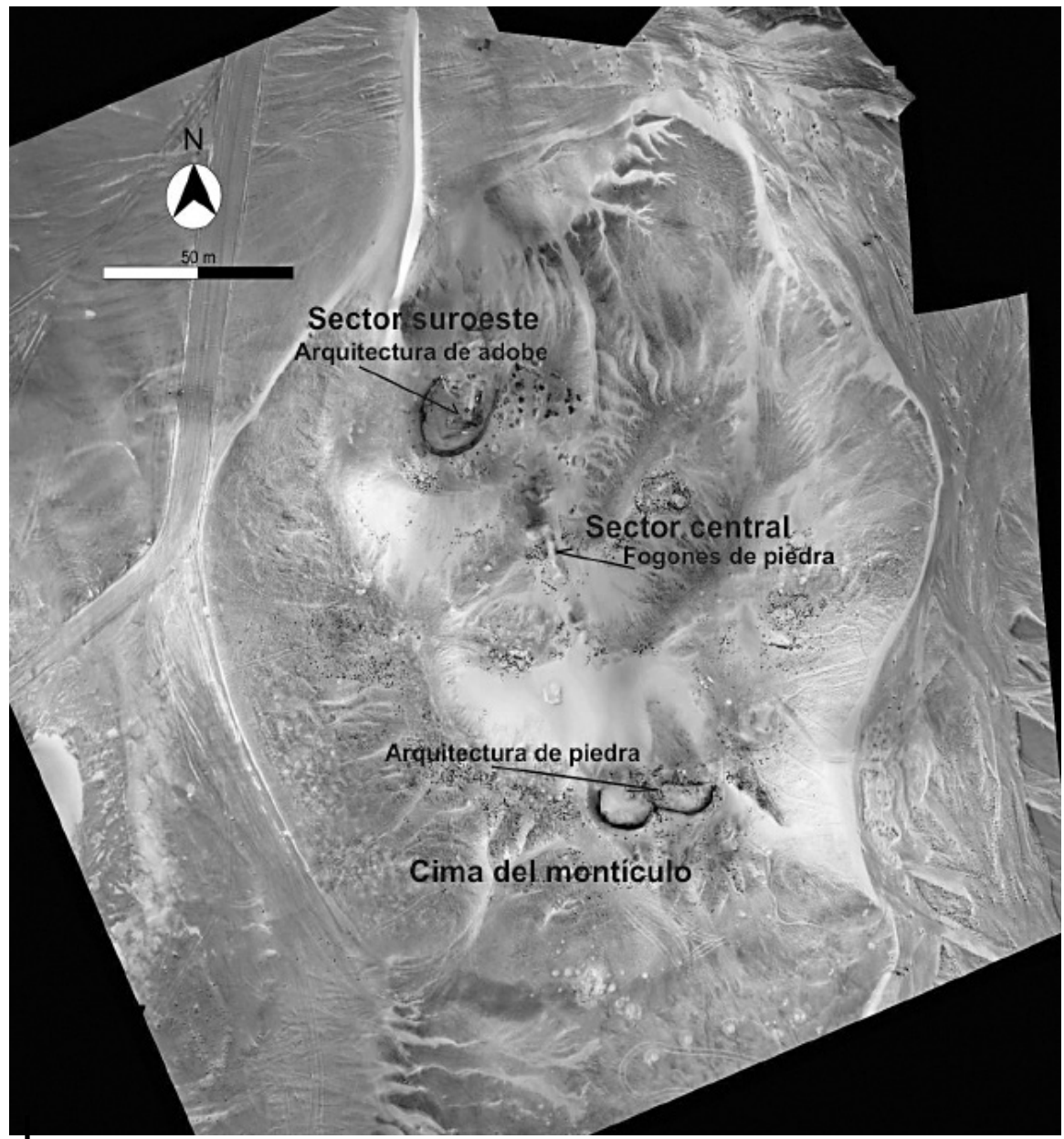

Figura 5 - Vista aérea del montículo Los Morteros donde se señalan los diferentes contextos hallados en el montículo y los sectores donde estos fueron encontrados

Los análisis hechos sobre el material recuperado muestran que las poblaciones tardías de Los Morteros (asociadas a la arquitectura de piedra y arcilla), usaron algodón para los envoltorios de los fardos funerarios y algunas otras prendas. Las semillas de este cultivo parecen haber sido usadas como combustible o para obtener aceite para cocinar pues siempre se hallan dentro de fogones. Así mismo, la palta, yuca, frijol, pallar, lúcuma, pacae, guayaba y el maíz formaron parte de la dieta de estas poblaciones. Sin embargo, la base de la alimentación durante los diferentes momentos de ocupación registrados, parece haber provenido del mar, a juzgar por la cantidad y variedad de especies halladas en este sitio. Dentro de estos, los peces de regular tamaño parecen haber sido fundamentales en la dieta de Los Morteros, pues son estas especies las más abundantes y recurrentes en los diferentes contextos. Así, especies como el suco (Paralonchurus peruanus), la 
lorna (Sciaena deliciosa), el bonito (Sarda chiliensis), la cachema (Cynoscion analis) y la corvina (Cilus gilberti), son las especies más importantes en el sitio. Especies pequeñas como la sardina (Sardinops sagax) y la anchoveta (Engraulis ringens) también están presentes, aunque en cantidades significativamente menores'1. Los moluscos marinos también fueron recursos importantes en el sitio: especies como machas (Mesodesma donacium), choro zapato (Choromytilus chorus), palabritas (Donax obesulus), chorito (Semimitylus algosus), lapas (Fisurella sp.) fueron hallazgos recurrentes y abundantes en los depósitos tardíos de Los Morteros.

Otras especies marinas que parecen haber sido importantes recursos económicos para la población de Los Morteros fueron los lobos marinos (Otaria flavescens y Arctocephalus australis) a juzgar por la abundancia de restos de esta especie en las capas más tardías del sitio. También se hallaron restos de delfines, marsopas y bufeos (Delphinus sp., Phocoena spinipinnis, Tursiops truncatus, respectivamente). Las aves costeras aparentemente fueron también recursos en Los Morteros. Las especies más recurrentes fueron piquero (Sula variegate), guanay (Phalacrocora bougainvillii), pelícano (Pelecanus thagus), cormorán (Phalacrocorax sp.), zarcillo (Larosterna inca) y gaviotas (Laridae sp.).

De los cinco sitios seleccionados para exploraciones a través de pozos de cateo, solo dos fueron intervenidos debido a restricciones de tiempo y presupuesto. Estos sitios fueron Conchal Viejo y Los Pescadores (fig. 2). Estas excavaciones tuvieron por objeto recuperar material orgánico apropiado para fechar estos sitios y entender así la ocupación precerámica de Pampa de las Salinas como un todo, estableciendo posibles relaciones temporales entre sitios. Las excavaciones en ambos sitios fueron exitosas y se logró obtener las muestras deseadas, las cuales se encuentra actualmente en análisis.

Por otro lado, las exploraciones geoarqueológicas de la paleobahía permitieron: 1) el reconocimiento de los diferentes microambientes que componen el paisaje de la bahía seca y, 2) exploración de la estratigrafía y los sedimentos de la paleobahía a través de la extracción de núcleos de suelo y la excavación de pozos de cateo. Las prospecciones identificaron diversos sectores que componen el paisaje de esta bahía seca, como por ejemplo relictos de un humedal y un bosque seco de Prosopis sp. Así mismo, estos trabajos identificaron tres nuevos sitios arqueológicos. Se trata de conchales de Mesodesmas sp., que, junto a los resultados de los análisis sedimentológicos y estratigráficos, permitirán fechar el retiro del mar hacia su posición actual y entender los eventos involucrados en ese proceso.

\section{INTERPRETACIONES PRELIMINARES}

Los trabajos hasta la fecha realizados en el sitio Los Morterosy en lazona arqueológica de Pampa de las Salinas, tanto en campo como en laboratorio, permiten esbozar

1 Para asegurar una recolección homogénea de restos, se usaron cernidores con doble malla de $1,5 \mathrm{~mm}$ y $3 \mathrm{~mm}$ de apertura, que permitieran recuperar especies grandes y pequeñas al mismo tiempo. 
una reconstrucción de la actividad humana durante el Periodo Precerámico en esta zona. Esta interpretación es aún preliminar pues todavía están en curso análisis y otros trabajos de campo (ver siguiente sección). Los resultados de los análisis radiocarbónicos estarán disponibles en las próximas semanas. No obstante, los datos hasta ahora obtenidos indicarían que las ocupaciones más tempranas en Los Morteros habrían estado relacionadas con poblaciones que explotaban recursos marinos de la zona y que vivían, tal vez intermitentemente, utilizando fogones de piedra y quizás viviendo en estructuras no permanentes. Tiempo después, se produjo una inversión considerable de recursos económicos y humanos para la construcción de grandes espacios, cuidadosamente hechos con adobe, piedra y arcilla, con muros internos enlucidos, pisos de arcilla y subdivisiones internas. Estos espacios son claramente de uso no domésticos y pueden haber servido para reunir cómodamente a más de 70 personas $\left(70 \mathrm{~m}^{2}\right)$ (fig. 3). Sin embargo, al ser estos espacios especiales, no se encontraron restos que hablen sobre el tipo de recursos usados o las actividades económicas realizadas. Durante este tiempo la población de Pampa de las Salinas parece haber aumentado, a juzgar por los asentamientos con arquitectura de piedra que se empiezan a construir cerca de Los Morteros. Es posible que en este tiempo la bahía de Las Salinas se encontrara aún en actividad y que los recursos marinos y costeros como pescados, moluscos, mamíferos, aves y vegetación hayan sido abundantes, permitiendo el aumento se la población local.

Nuestras excavaciones indican que una de las ocupaciones más tardías de Los Morteros se refleja en la arquitectura de piedra hallada en la cima del montículo. Esta población también estuvo ligada a la explotación de los recursos marinos y costeros de esta zona; pero al parecer, también estuvieron explotando la salina que quedó expuesta, tras el receso del mar hacia su posición actual. A esta última actividad se relacionan los morteros de piedra que se observan en muchos sectores del montículo, de los cuales deriva el nombre de este sitio. Al parecer, en las últimas fases de ocupación del sitio, los pobladores de Los Morteros explotaron recursos marinos y costeros, y utilizaron morteros de piedra para procesar la sal que extraían de la salina local. Muchos de los asentamientos aledaños a Los Morteros seguían siendo ocupados, pero también surgen nuevos sitios. Esto lo demuestra el hallazgo de tres conchales de machas (Mesodesma sp.) al interior de la bahía seca, en la parte noreste, los cuales contienen restos muy parecidos a aquellos hallados en el sitio Cochal Viejo, ubicado al suroeste de la paleobahía (fig. 2), en el cual se hallaron además unos pocos fragmentos de cerámica temprana en superficie.

\section{INVESTIGACIONES EN CURSO}

Diversos análisis de laboratorio aún se encuentran en curso, entre ellos los análisis radiocarbónicos que fecharán los sitios y contextos excavados, los cuales servirán para confirmar o descartar la secuencia de ocupaciones que hasta ahora se plantea. Adicionalmente, en este año 2014 se vienen realizando trabajos de campo que involucran toma de muestras de sedimentos y núcleo de suelo de la paleobahía, 
así como también se realizarán excavaciones arqueológicas en Los Morteros y los sitios aledaños que habían sido antes seleccionados para excavaciones a través de pozos de cateo. Estas excavaciones buscan complementar la información hasta ahora obtenida en términos de fechas para los sitios vecinos a Los Morteros, así como también entender mejor los contextos registrados en este sitio. Los análisis de sedimentos buscan entender los procesos involucrados en la transformación de este medio, de una bahía altamente productiva al medio hiperárido que es actualmente.

\section{Agradecimientos}

Las investigaciones del Proyecto Arqueológico Los Morteros-Pampa de las Salinas han sido posibles gracias al apoyo de diferentes instituciones como la Universidad de Maine, el Proyecto NSF "Long-Term Human Ecodynamics in Coastal Peru" Award \#ARC-1152156, the National Geographic Society-Waitt Grant, the Churchill Exploration Fund, el Instituto Francés de Estudios Andinos-IFEA (UMIFRE 17-MAEDI/CNRS USR 3337 América Latina, the Graduate Student Government de la Universidad de Maine y FERCO International Fund.

\section{Referencias citadas}

ALVA, W., 1986 - Salinas de Chao, frühe Siedlung in Nord-Peru asentamiento temprano en el norte del Perú, 169 pp.; München: C. H. Beck. Beitriige zur Allegemeinen und Vergleichenden Archiiologie 34.

CÁRDENAS, M., 1999 - El Periodo Precerámico en el valle de Chao. Boletín de Arqueología PUCP, 3: 141-169; Lima: Fondo Editorial de la Pontificia Universidad Católica del Perú.

SANDWEISS, D., KELLEY, A., BELKNAP, D., KELLEY, J., RADEMAKER, K., REID, D., 2010 - GRP Identification of an early monument at Los Morteros in the Peruvian coastal desert. Quaternary Research, Vol. 73 (3): 349-448. 